\title{
HISTOPATHOLOGICAL STUDIES OF THE EFFECTS OF CYTOCHROME C ON CARBON TETRACHLORIDE- INDUCED LIVER DAMAGE AND ON THE LIVERS OF AGED RATS
}

\author{
Haruo OHNISHI, Yutaka HAYASHI, Nobuhisa OGAWA, \\ Gompachi YAJIMA* and Kaoru AIHARA* \\ Rescarch Laboratory, Mochida Pharmacentical Co., L.td., Kita-ku, Tokyo and \\ Department of Pahology. Nippon Medical College, Bunky-ki*. Tokyo. Japam
}

Accepted November 5, 1973

\begin{abstract}
Histopathological changes of the liver by carbon tetrachloride included vacuolar necrosis of hepatic cells, cellular infiltration, an increase in fat droplets, a decrease in glycogen particles and a degenetation and a decrease in the number of rough surfaced endoplasmic reticula. These changes were prevented by the administration of cytochrome $c$. These findings were consistent with the results of previous biochemical studies that cytochrome c prevents an increase in transaminase activity, an enhancement of BSP retention, an increase in hepatic neutral fat and a decrease in hepatic glycogen induced by carbon tetrachloride. Meanwhile, histopathological characteristics of the liver of aged rats included an increase in number of vacuoles in the cells, disintegration of and decrease in hepatocyte component. a decrease in the number of glycogen particles and an increase in fat droplets and consumptive substance. The histopathological changes of aging were either alleviated or inhibited completely with cytochrome $c$. The conclusion is in conformity with previous reports indicating that cytochrome $c$ improved the liver functions of aged rats and decreased lipids of the liver.
\end{abstract}

The authors have previously reported $(1,2,3,4,5)$ biochemical studies on the effects of cytochrome $\mathrm{c}$ in preventing experimental hepatic damage caused by carbon tetrachloride and in improving liver function which has undergone spontaneous deterioration due to aging. In the present experiment the effects of cytochrome $c$ on carbon tetrachloride-induced liver damage and on the livers of aged rats were studied histopathologically.

\section{MATERIALS AND METHODS}

1) Effects of cyochrome 'on carbon tetrachloride-induced liver damage $(1,3)$

Liver damage was generated by giving carbon tetrachloride, $0.2 \mathrm{ml} / \mathrm{kg} / \mathrm{day}$ i.p. for 3 consecutive days to male rats of the Donryu strain weighing approx. $250 \mathrm{~g}$.

The administration of cytochrome c. $100 \mathrm{mg} / \mathrm{kg} /$ day i.m. into the thigh or in the oral form of enteric-coated granules was performed for four days, slarting one day prior to the initiation of the administration of carbon tetrachloride. The animals were bled to death on the day after completion of the administration. Immediately thereafter, the liver of each animal was excised for histopathological studies.

2) Effects of cytochrome $c$ on the livers of aged rats $(2,4,5)$

Cytochrome c. $100 \mathrm{mg} / \mathrm{kg} /$ day i.m. was given to 500 day-old male rats of the Donryu 
strain into the thigh or in the oral form of enteric-coated granules for 21 days. The animals were bled to death on the day after completion of the administration. Immediately thereafter, the liver of each animal was excised for histopathological studies.

3) Preparation of specimens for light microscopy

The liver was fixed in a solution of $10 \%$ formalin with $0.1 \mathrm{M}$ phosphate buffer solution of $\mathrm{pH} 7.4$, embedded in paraffin and stained with hematoxylin-eosine and PAS for light microscopic examination.

4) Preparation of specimens for electron microscopy

For fixation of the tissue, a solution of $2.5 \%$ glutaraldehyde with $0.05 \mathrm{M}$ cacodylate buffer of $\mathrm{pH} 7.4$ and a solution of $1 \%$ osmic acid were used.

The liver specimens were prefixed with glutaraldehyde for $2 \mathrm{hr}$ at a temperature of $4 \mathrm{C}$ and further fixed with osmic acid for $2 \mathrm{hr}$ at the same temperature. The specimens were then dehydrated with ethanol, embedded in Epon 812 (6) and sectioned in the thickness of 0.1 / with a Porter Blum MT-1 microtome. The ultrathin sections were then double stained with uranium acetate and lead citrate (7) for electron microscopy.

The specimens were examined using Hitachi HU-1 1 D electron microscope at an accleration voltage of $50 \mathrm{KV}$.

\section{RESULTS}

1) Effects of cyfochrome $c$ on carbon tetrachloride-induced liver damage

Light microscopic findings: The liver lobule of 70 day-old control rats was normal and cellular degeneration was not observed (Fig. 1).

Following administration of carbon tetrachloride, vacuolar degeneration cells and balloon cells were observed around the central vein and the middle lobular zone. Significant cellular infiltration, including fibroblass, from Glisson's capsule was noted (Fig. 2)

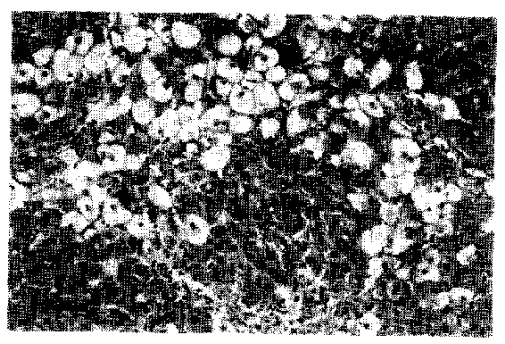

FIci. 2. Hepatic cells of 70 day-old rats after the administration of carbon tetrachloride. Marked cellular infiltration including fibroblasts was noted. Marker, $20 \mathrm{~mm}$.

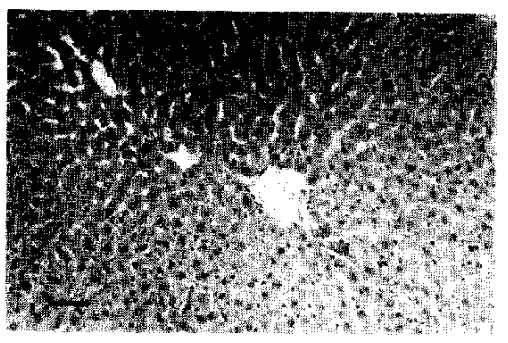

FIc. I. Hepatic cells of 70 day-old rats. L.jver lobule was normal. Marker, $20,: m$.

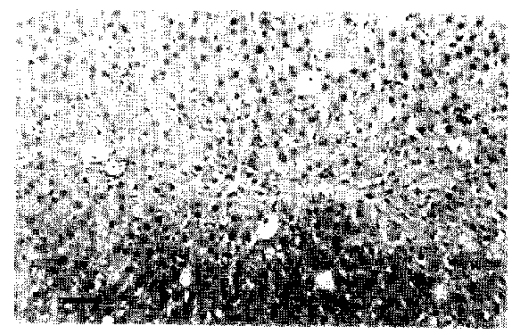

Fig. 3. Effects of p.o. administration of cytochrome $c$ on hepatic cells of 70 day-old rats given carbon tetrachloride. Despite partially vacuolated cells, the cells are mostly normal. Marker, 20 /m. 
Furthermore, increased fat droplets, sinusoidal stenosis and decreased PAS-positive granules were observed. Although the above histopathological changes caused by carbon tetrachloride were also observed in the groups given cytochrome $\mathrm{c}$ i.m. and orally, the severity of the changes noted in the above groups was less than that observed in the group given carbon tetrachloride, and particularly significant was the inhibition of cellular infiltration noted in the cytochrome c groups (Fig. 3).

Electron microscopic findings: Hepatocyte components of the 70 day-old control rats were well maintained (Fig. 4). As a result of the administration of carbon tetracthloride, a decrease and vacuolating of rough surfaced endoplasmic reticula (Fig. 5), an increase in fat droplets and vacuolar degeneration of cells (Fig. 6), a decrease in glycogen particles and a slight decrease in milochondria and a slight obscurity of its cristae were observed.

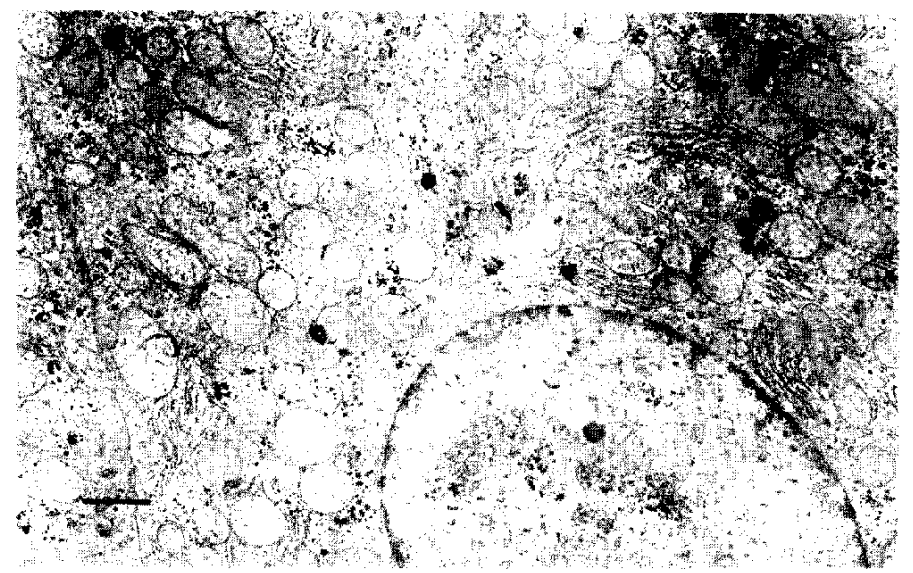

Fici. 4. Fine structure of hepatic cells of 70 day-old rats. Cellular elements were maintained well. Marker, 1 : $\mathrm{m}$.

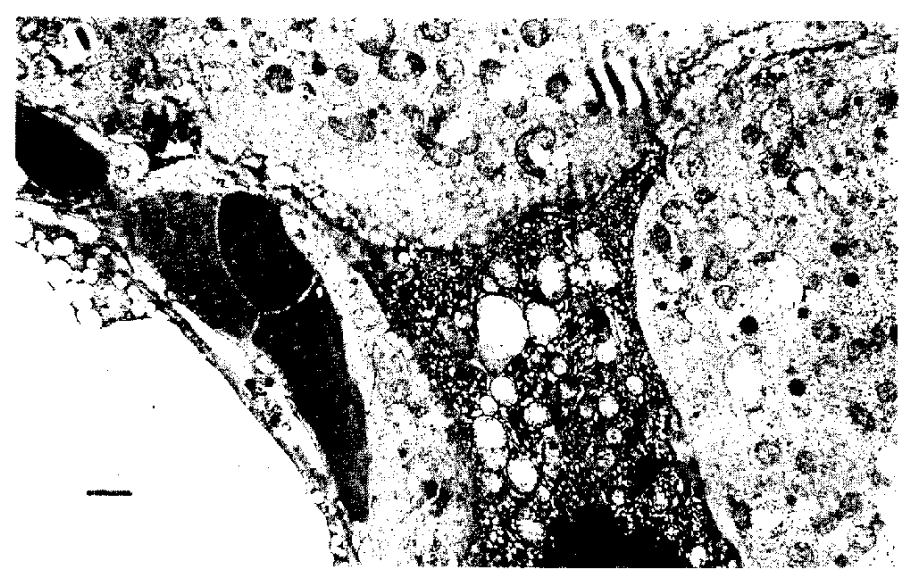

Frc. 5. Fine structure of the liver of 70 day-old rats given carbon tetrachloride. $A$ decrease and expansion of rough surfaced endoplasmic reticula were noted. Marker, $1,19$. 


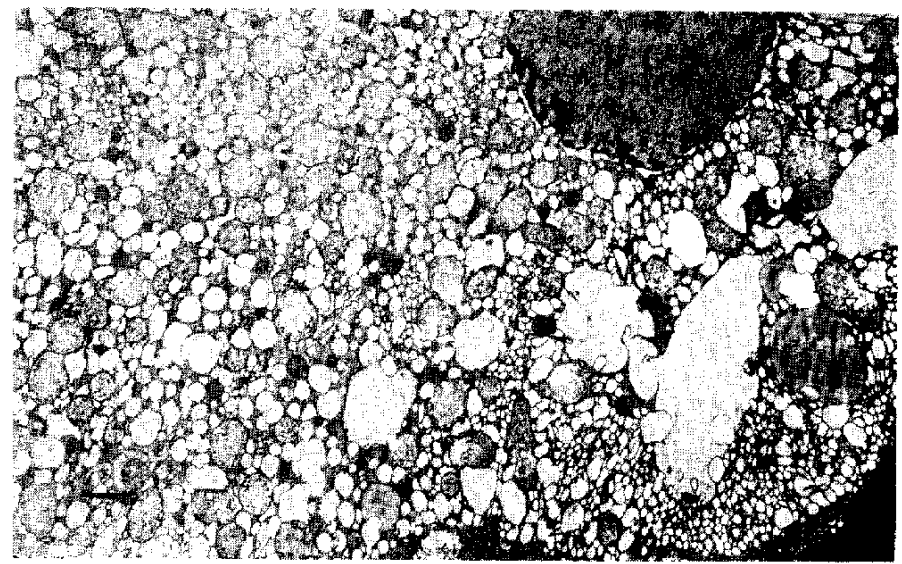

Fici. 6. Fine structure of the liver of 70 day-0)ld rats given carbon tetrachloride. Increased fat droplets and vacuoles were observed. Marker, $1, \mathrm{~m}$.

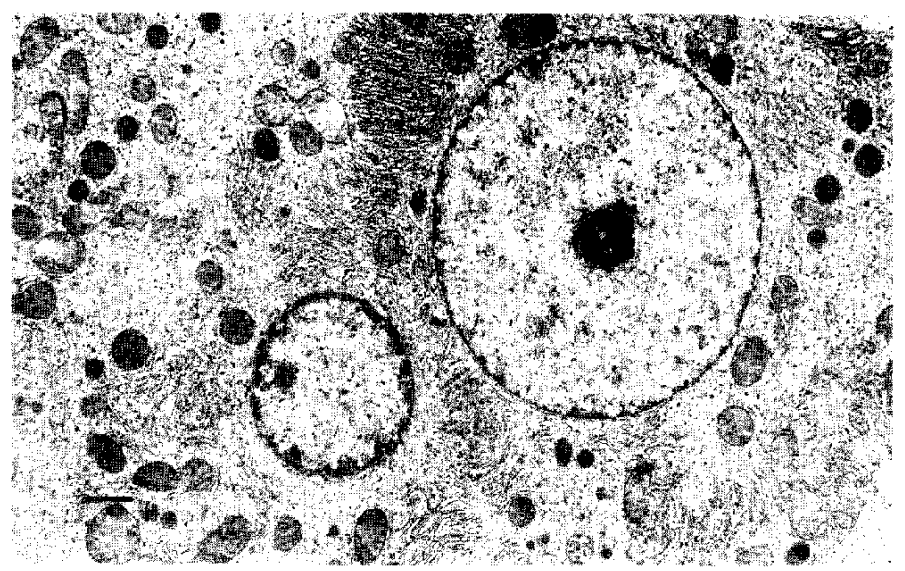

FIG. 7. Effects of p.o, administration of cytochrome $c$ on the fine structure of the liver of 70 day-old rats given carbon tetrachloride. Despite partial expansion of rough surfaced endoplasmic reticula, cellular elements were well maintained. Marker, 1 m.

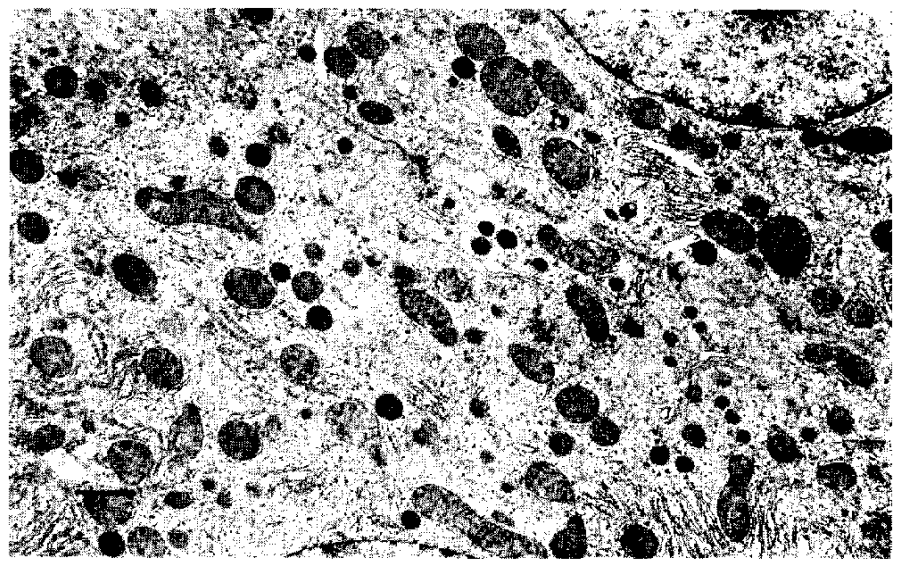

FIG. 8, Effects of the p.o. administration of cytochrome $\mathrm{c}$ on the fine structure of the liver of 70 day-old rats given carbon tetrachloride. Marked proliferation of Golgi bodies was observed. Marker, $1, \mathrm{~m}$. 
Changes in the fine structure of the liver induced by carbon tetrachloride tended to be inhibited by the p.o. administration of cytochrome c.

The rough surfaced endoplasmic reticula showed slight expansion but no decrease was observed, and the structure of the mitochondria and glycogen were well maintained (Fig. 7). Fat droplets and vacuolar degeneration were observed to be few. A marked proliferation of the Golgi bodies was partially observed (Fig. 8).

Similar findings were also obtained after the i.m. administration of cytochrome c.

2) Effeces of crochrome $c$ on the livers of aged rats

Lishn microscopic findings: An increase in the number of vacuoles in the hepatic cells was observed in 500 day-old rats (Fig. 9). The number of vacuoles that increased with aging showed a decrease following the administration of cytochrome c (Fig. 10). After the administration of cytochrome $c$ to 500 day-old rats, a marked increase in the number of hepatic cells and binuclear cells was noted (Table 1).

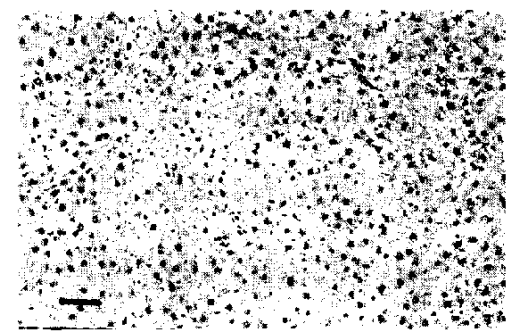

Fici. 9. Cells of the liver of 500 day-old rats. Vacuolar cells were noted. Marker, 20 :m

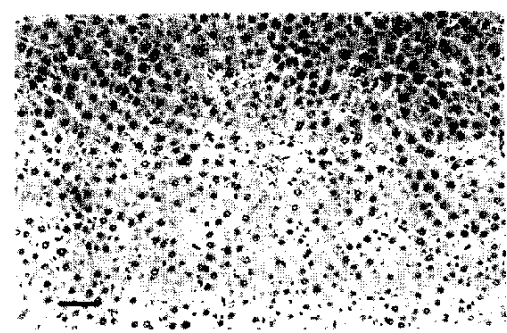

Fici. 10. Effects of the p.o. administration of cytochrome $c$ on the hepatic cells of 500 day-old rats. A decrease in the number of vacuolar cells was noted. Marker, $20 \mathrm{fm}$.

TabLl 1. Effects of cytochrome $\mathrm{c}$ on number of hepatic cells in 500 day old rats.

\begin{tabular}{|c|c|c|c|c|}
\hline Adm. & & $\begin{array}{l}\text { Untreated } \\
\text { control }\end{array}$ & $\begin{array}{c}\text { Cytochrome c } \\
(100 \mathrm{mg} / \mathrm{kg}) \mathrm{im} . \mathrm{m}\end{array}$ & $\begin{array}{l}\text { Cytochrome c } \\
(100 \mathrm{mgkg}) \text { p.o. }\end{array}$ \\
\hline No. of rats & & 4 & 4 & 4 \\
\hline No. of Hepatic Colls & $10.195 \mathrm{~mm}^{2}$ & 131 & $154 \quad 5^{*}$ & $2 * *$ \\
\hline No. of Binucleus Hepatic Cells & $10.195 \mathrm{~mm}^{2}$ & $8.5: 1.7$ & $12.0 \div 5.3$ & $20.0 \cdot 2.1^{*}$ \\
\hline
\end{tabular}

Results are given as means s.c.

Significant differences from 500 days, untreated rat group are marked : ** $(p \quad 0.01)$; $*$ (p 0.05$)$

Electron microscopic findings: Characteristic of the fine structure of the liver of 500 day-old rats was the disintegration of hepatocyte components, wherein dispersion of mitochondria, fragmentation of rough surfaced endoplasmic reticula (Fig. 11, 12) and an increase in consumptive substance were observed. Following the p.o. administration of cylochrome $c$, the disintegration of hepatocyte components was alleviated. Namely, an increase in the number of mitochondria (Fig. 13), retention of the structure of the mito- 


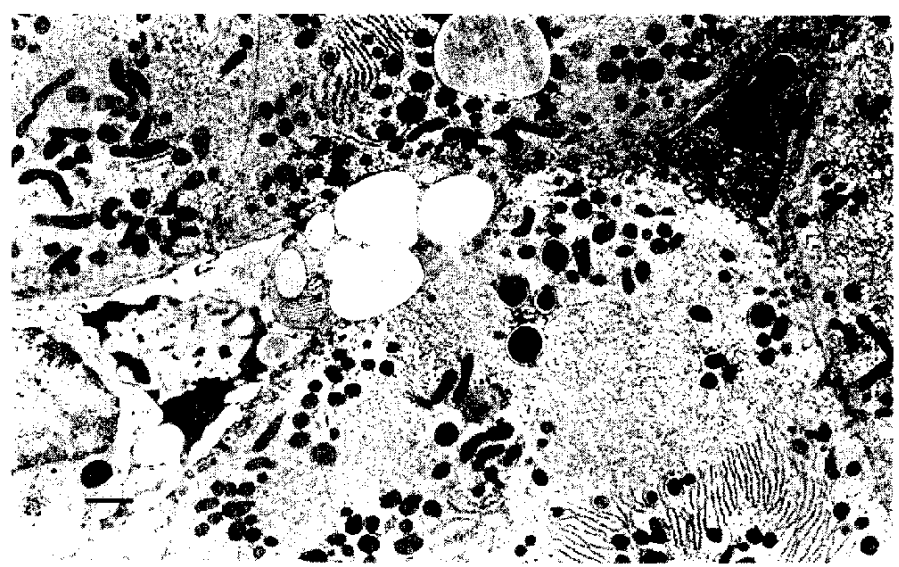

Fic, 11. Fine structure of the liver of 500 day-old rats. Dispersion and decrease in cellular elements were noled. Marker, $\mathrm{I}_{i} / \mathrm{m}$.

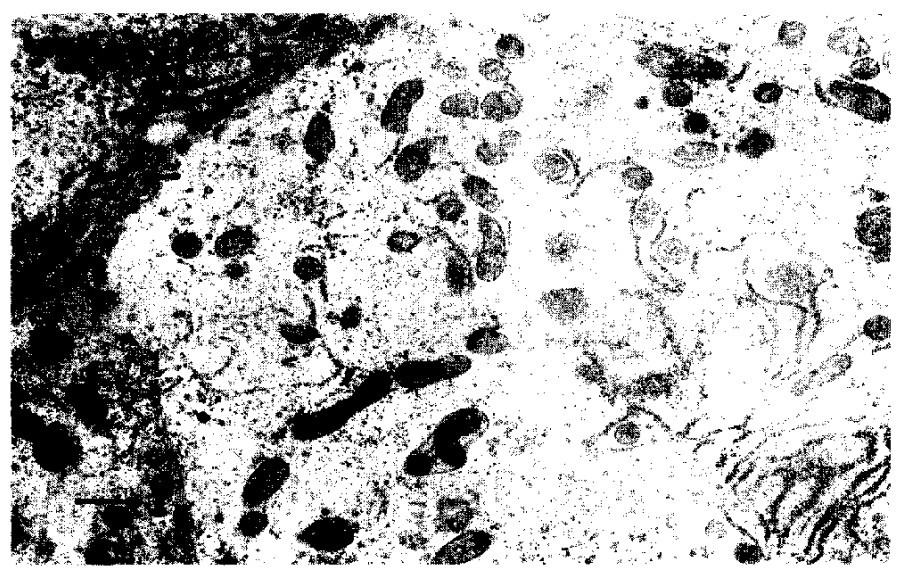

Fici. 12. Fine structure of the liver of 500 day-old rats. Disintegration of cellular clements was observed. Marker, 1 \%m.

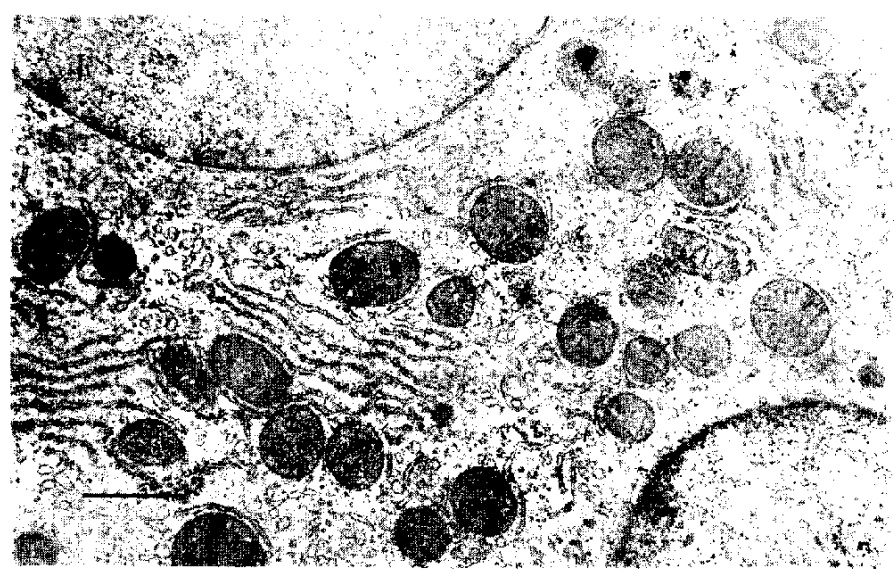

Fici. 13. Effects of p.o. administration of cytochrome $c$ on the fine structure of the liver of 500 day-old rats. A decrease in cellular elements was not observed, and the structure was maintained relatively well. Marker, 1 , $m$. 


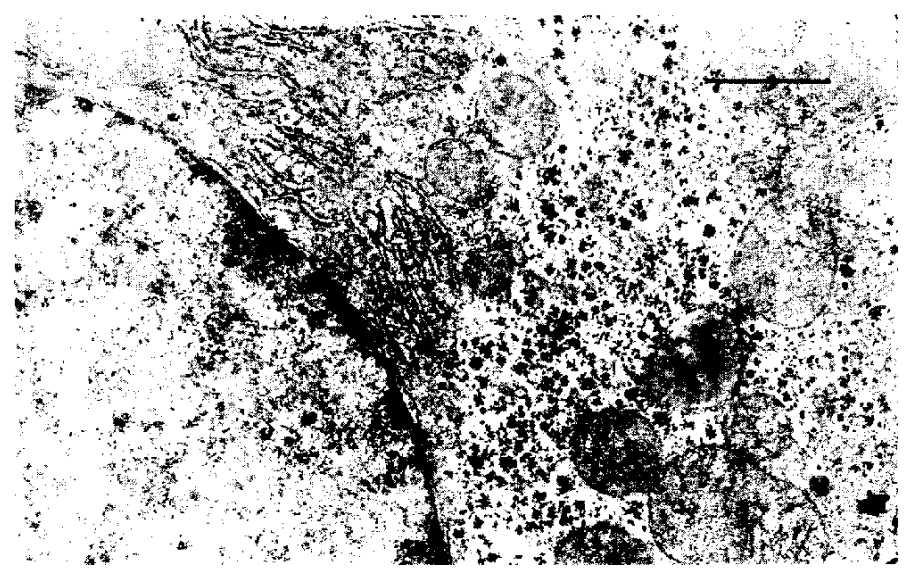

FIci. 14. Effects of the p.o. administration of cytochrome $c$ on the fine structure of the liver of 500 day-old rats. Glycogen granules were maintained well. Marker. 1 tm.

chondria and rough surfaced endoplasmic reticula (Fig. 14) and an increase in the number of glycogen particles were more marked than in the untreated 500 day-old rats.

Similar findings were also noted in the livers of the group treated with i.m. administration of cytochrome $\mathrm{c}$.

\section{DISCUSSION}

1) Effects of cytochome a on carbon tefrachloride-induced liver damage

Histopathological changes of the liver by carbon tetrachloride included vacuolar necrosis of hepatic cells, cellutar infiltration, an increase in fat droplets, a decrease in glycogen particles and a degeneration and a decrease in the number of rough surfaced cndoplasmic reticula. These histopathological changes were prevented by the administration of eytochrome c. The fact that cytochrome $c$ prevents an increase in transaminase activily, an enhancement of BSP retention, an increase in hepatic neutral fat and a decrease in hepatic glycogen brought about by carbon tetrachloride has been reported elsewhere $(1,3)$. and the findings were presumably prodiuced by the same working mechanism. The observation that cytochrome c prevents the degencration of rough surfaced endoplasmic reticula (8) produced by carbon tetrachloride is of significance in considering the working mechanism of this hemeprotein.

Despite our reports citing a decrease in tissue respiation of the hepatic mitochondria. a decrease in the levels of cytochrome $a, b$ and $c$ and a marked decline in the level of hepatic ATP (3). the degereration of the hepatic mitochondria was not as marked as expected.

On the other hand, the proliferation of Golgi bodies observed in the group given $c y-$ tochrome c maty suggest increased secretion of lipoprotein (9).

2) Efferts of cyochrome (" on the livers of aged rats

Histopathological characteristics of the liver of aged rats included an increase in the number of vacuoles in the cells, disintegration of and decrease in hepatocyte component, 
a decrease in the number of glycogen particles and an increase in fat droplets and consumptive substance. The histopathological changes of aging were either alleviated or inhibited completely with cytochrome c. Cytochrome $c$ also improved the function of the livers of aged rats, a fact which was in conformity with previous reports $(2,4)$ indicating that lipids of the liver decrease.

Furthermore, it is said the number of hepatic cells decreases with aging (10), and a marked increase in the number of hepatic cells and binuclear cells was noted following the administration of cytochrome $c$. This fact is of great significance in improving hepatic function.

\section{REFERENCES}

1) Akutsu, T., OhNishı, H., Ito, C. AND OGawa, N.: Pharmacometrics 4, 397 (1970) (in Japanese)

2) Ohnishi, H., Tsukcda, S., Hayashi, Y., Ogawa, N., Yajma, G., Masugi, Y., Aihara, K. AND SUZUKI, K.: Nature, 239, 84 (1972)

3) OrNishi, H., Tsukuda, S. and OGawa, N.: Japan. J. Pharmacol. 23, 881 (1973)

4) Ohvishi, H., Tsukuda, S. And Ofawa, N.: Japan. J. Pharmacol. 24, 15 (1974)

5) Ohnishi, H., Tsukuda, S. And Ogawa, N.: Japan. J. Pharmacol. (in press)

6) LUFT, J. H.: J. biophy. and biochem. Cytol. 9, 409 (1961)

7) ReYnolds, E.S.: J. cell Biol. 17, 208 (1963)

8) Ganote, C.E. and Rosevthal, A.S.: Lab. Invest. 19, 382 (1968)

9) Heimberg, M., Weinstein, I., Dishmon, G. And Fried, M.: Am. J. Physiol. 209, 1053 (1965)

10) TAlf HI, H.: J. Geriatrics 2, 108 (1965) (in Japanese) 